\title{
The da Vinci Xi: a review of its capabilities, versatility, and potential role in robotic colorectal surgery
}

This article was published in the following Dove Press journal:

Robotic Surgery: Research and Reviews

28 July 2017

Number of times this article has been viewed

\author{
James Chi-Yong Ngu' \\ Charles Bih-Shiou Tsang ${ }^{2,3}$ \\ Dean Chi-Siong Koh ${ }^{2,3}$ \\ 'Department of General Surgery, \\ Changi General Hospital, ${ }^{2}$ Department \\ of Surgery, Yong Loo Lin School \\ of Medicine, National University \\ of Singapore, ${ }^{3}$ Colorectal Clinic \\ Associates, Mount Elizabeth Novena \\ Specialist Center, Singapore
}

\begin{abstract}
The $\mathrm{Xi}$ is the latest da Vinci surgical system approved for use in colorectal surgery. With its novel overhead architecture, slimmer boom-mounted arms, extended instrument reach, guided targeting, and integrated auxiliary technology, the Xi manages to address several limitations of earlier models. The versatility of this new system allows it to be implemented in a wide range of colorectal procedures - from complex multiquadrant colectomies to challenging mesorectal dissections in the pelvis. While commonly criticized for its cost and prolonged operative time, robotic colorectal surgery holds the potential for enhanced ergonomics, superior precision, and a reduction in the learning curve involved in training an expert surgeon. This review appraises the existing literature on robotic colorectal surgery while elaborating how the improved capabilities of the Xi serve to usher in a new era of minimally invasive colorectal surgery.

Keywords: review, multiquadrant, minimally invasive, colorectal, surgery
\end{abstract}

\section{Introduction}

Minimally invasive techniques have been incorporated into colorectal surgery for more than three decades. The German gynecologist Kurt Semm performed the first laparoscopic appendectomy in $1980,{ }^{1}$ and the first case series of laparoscopic colectomies was published by Jacobs et al in 1991. ${ }^{2}$ Since then, numerous authors have compared the outcomes of laparoscopic versus open colorectal surgery, with the more recent articles citing superior short-term outcomes and comparable oncological results. ${ }^{3-6}$ However, the adoption of laparoscopic colorectal surgery remained slow due to the technical complexity of such procedures. ${ }^{7}$ Data from the American Board of Colon and Rectal Surgery (ABCRS) showed that 3.6\% of major colorectal operations were performed laparoscopically in 1994, and the increase was only up to $24.3 \%$ by $2005 .{ }^{8}$ Data from the Surgical Care and Outcomes Assessment Program (SCOAP) subsequently demonstrated an increase from $23.3 \%$ in 2005 to $41.6 \%$ in $2010 .{ }^{9}$ Part of the challenge arises from the incongruity between the quality of surgery required for good oncological outcomes and the technology of available equipment. For example, the ability to achieve appropriate traction and precise dissection in the pelvis during laparoscopic total mesorectal excision (TME) has been limited by the restrictive single-jointed movements of straight-shaft laparoscopic instruments. The fulcrum effect of laparoscopic ports also causes the instrument tips to move paradoxically to that of the surgeon's hands.

Many authors have also published on robot-assisted laparoscopic colorectal surgery since the first robotic colectomy was described by Weber et al in $2002 .{ }^{10-17}$ In general, authors have found robotic surgery to be feasible and safe, referring to it as 
a "promising" technology that may have a role in selected patients, for example, obese male rectal cancer patients undergoing radical proctectomy. While some studies have reported no significantly superior outcomes when compared with laparoscopy, others have shown a trend toward lower conversion rates and superior circumferential resection margins in robotic surgery. A consistent conclusion in the majority of papers is that robotic colorectal surgery tends to be associated with a higher cost and a longer operative time. $^{13-17}$

However, the quality of these studies and consequently the conclusions drawn should be subjected to greater scrutiny. Most of these publications have been either case series or retrospective comparative studies. Another criticism would be that the laparoscopic experience of these surgeons often surpassed their exposure to robotics. ${ }^{18}$ In addition, while there have been numerous meta-analyses evaluating robotic colorectal surgery, most of the articles reviewed have been non-randomized trials with variable quality, and they were often repeatedly cited. All eight studies reviewed by Trastulli et al were non-randomized, two of which were retrospective. ${ }^{19}$ Of the 24 studies included in the meta-analysis by Zhang et al, 17 were retrospective, and only the two by JiménezRodríguez et al and Park et al were randomized trials. ${ }^{20-22}$ All seven articles in the 2014 publication by Xu et al were included in a 2015 publication by Chang et al, and some of these articles also contributed to half of the meta-analysis by Zarak et al. ${ }^{11,12,22-26}$ Between 2014 and 2016, three different journals separately published meta-analyses on robotic versus laparoscopic rectal cancer surgery - all included the same eight studies and 1229 patients. ${ }^{27-29}$ Two of these publications were authored by the same group. As a testament to sound statistics, all three articles arrived at the same results and conclusions. Evidently, the comparison between robotics and conventional laparoscopy should remain the subject of further well-designed prospective controlled trials.

Another noteworthy point is that almost all of the studies on robotic colorectal surgery have been conducted using the older versions of the da Vinci (dV) surgical systems, which were criticized for their bulky external arms and limitations in maneuverability. These robots were beleaguered by complex port placement configurations and docking procedures, effectively precluding their widespread application in multiquadrant colorectal surgery. The dV Xi (Intuitive Surgical, Sunnyvale, CA, USA), launched in 2014, serves to address many of the limitations posed by the older systems. A literature search using "da Vinci" and "Xi" title fields retrieved approximately ten articles specific to the Xi, of which only four studies compared its performance to that of the older Si model. ${ }^{30-33}$ Multivariate analysis of the results by Ozben et al demonstrated that the $\mathrm{Xi}$ was an independent factor associated with a reduced console time. ${ }^{30}$ Morelli et al also reported a significantly shorter operative time using the Xi for robotic TME. ${ }^{32}$ With its overhead architecture, slimmer boom-mounted arms, extended instrument reach, guided targeting, and integrated auxiliary technology, the Xi has the potential to allow even novice robotic surgeons to overcome the traditional barriers of operating with a robot. The pioneer institution to install the $\mathrm{Xi}$ in India concluded that the system makes docking user-friendly and instrument usage safer for less-experienced users. ${ }^{34}$ To date, one of the few criticisms of the new $\mathrm{Xi}$ design is that the additional height of the patient cart potentially poses a problem for operating rooms with ceiling attachments..$^{35}$ This review focuses on how the advancements in the Xi contribute to its versatility of application in colorectal surgery, discussing the results from available reports on the technology.

\section{Versatility of the $\mathbf{X} \mathbf{i}$ in colectomies and multiquadrant surgery}

Earlier generations of $\mathrm{dV}$ robots required either a hybrid laparoscopic-robotic approach or intraoperative redocking to complete multiquadrant surgeries, for example, a low anterior resection incorporating a complete splenic flexure mobilization or an extended right hemicolectomy. ${ }^{36,37}$ Hybrid procedures and the use of additional consumables inevitably compounded costs, and repeated dockings prolonged the operative time of these procedures. As a result, many authors concluded that robotics was not suitable for the wide operative field required in colorectal surgery.

With the Xi, early reports have unanimously concluded that the new system simplifies the docking procedure and makes single docking feasible even for complex multiquadrant colorectal procedures. ${ }^{30-34,38}$ With its rotating boommounted arms, the Xi surgical cart can achieve four-quadrant anatomical access while being docked from any position around the patient. The docking procedure is also facilitated by laser targeting and improved cannula mounts. These features allow the use of a simplified "linear" port configuration and an abbreviated docking time (Figure 1). Authors have described the feasibility of applying a common Xi port configuration for all left-sided multiquadrant procedures. ${ }^{38}$ By modifying the angle of the "offset costofemoral line" along which the robotic ports were placed, dissection was possible from the splenic flexure down to the pelvis without redocking the robot or repositioning the patient. A more 

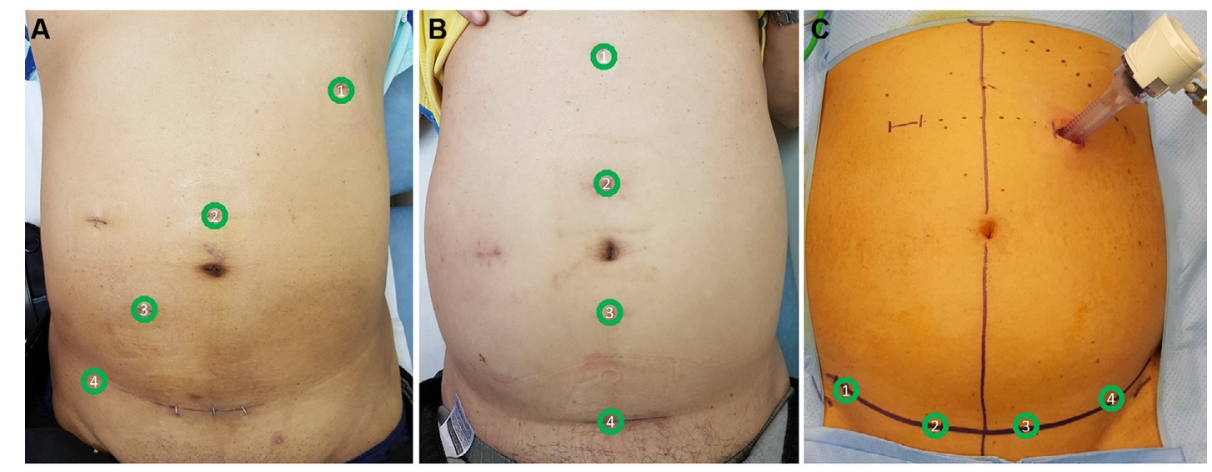

Figure I Xi "linear" port configurations.

Notes: (A) The oblique offset costofemoral, (B) vertical midline, and $(\mathbf{C})$ transverse suprapubic port configurations with the respective port positions as numbered.

longitudinal port configuration would facilitate mobilization of the colon, whereas a transverse layout would render pelvic dissection more ergonomic. ${ }^{38}$ This "single-docking single-phase" capability of the Xi has also been reported by Ozben et al, ${ }^{30}$ Protyniak et al, ${ }^{31}$ and Tamhankar et al ${ }^{34}$ in their series. Compared to the older $\mathrm{dV} \mathrm{Si}$, a higher rate of splenic flexure mobilization was achieved by Protyniak et $\mathrm{al}^{31}$ and Morelli et $\mathrm{a}^{132}$ using the Xi. Analyzing the data in the first six months of installing the $\mathrm{Xi}$, Hagen et al reported that they were able to perform all their low anterior resections and gastric bypasses as totally robotic procedures instead of, previously, hybrid approaches. ${ }^{33}$

While the earlier generations of $\mathrm{dV}$ robots required their external arms to be widely spaced in order to maximize the working field, the opposite is true for the $\mathrm{Xi}$-the horizontal FLEX joints of the Xi need to be compacted, leaving onefist-width spacing between each arm. This configuration allows the arms to move in parallel with each other, avoiding collision between the instrument carriages and the adjacent arm during multiquadrant surgery (Figure 2). In the event that the operative field extends beyond the alignment of the Xi FLEX joints, either the robot arms can be manually redirected towards the new target anatomy, or the entire boom can be reoriented by undocking the ports and performing a retargeting. ${ }^{32,38}$

The functionality of the $\mathrm{Xi}$ is also augmented by adjustments that can be made to the patient clearance joints of each robot arm. As patient clearance is increased, the arm joints rotate axially clockwise away from the patient and the preceding arm, resulting in the external arm assuming a steeper angle and creating more space between the arm and the patient (Figure 3). Conversely, instrument reach beyond the target zone can be increased at the expense of patient clearance. At maximum instrument reach, the $\mathrm{Xi}$ arms gain $28^{\circ}$ of movement over the $\mathrm{Si}$. In general, the arms that are docked to the iliac fossa ports would require more patient clearance in order to avoid collision with the thighs of the patient. ${ }^{38}$

Another feature of the $\mathrm{Xi}$ is the redesigned $8-\mathrm{mm}$ endoscope. The camera, endoscope, and cable have been integrated into a small, handheld design. Apart from the enhanced ergonomics and ease of use in hybrid laparoscopy, the $\mathrm{Xi}$ endoscope is also able to be inserted through any of the 8-mm robotic ports - a feature known as "port hopping". Compared to the bulky endoscope of the earlier $\mathrm{dV}$ robots which could only be inserted through $12-\mathrm{mm}$ ports, users
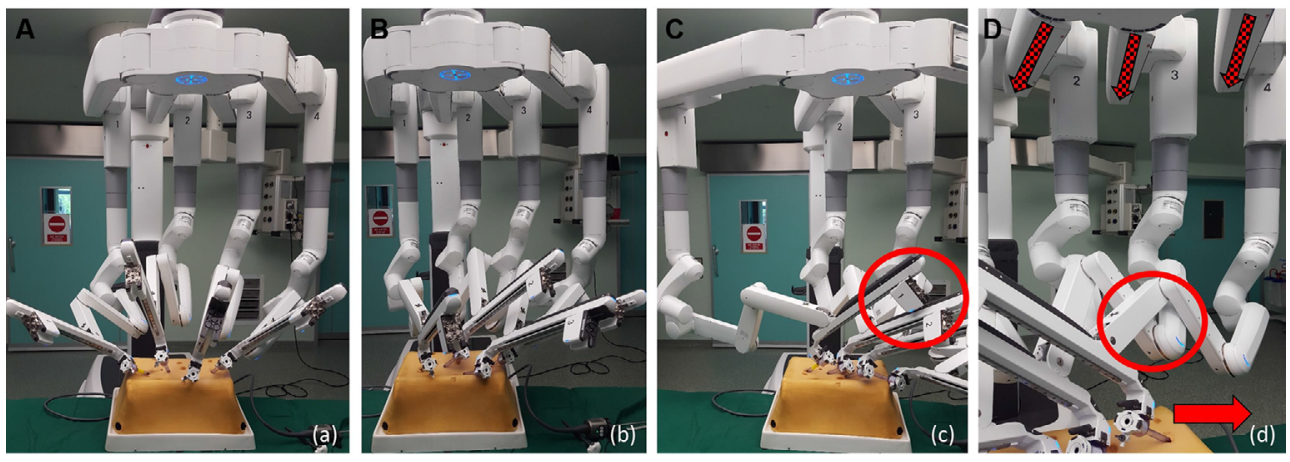

Figure 2 FLEX joints.

Notes: (A) FLEX joints should be compacted, leaving one-fist-width spacing between each robotic arm (B) to allow the robotic arms to move in parallel. (C) The instrument carriage tends to clash with the adjacent arm (circle) when the FLEX joints are spaced apart. (D) The robotic arms also clash (circle) when the operative target (solid arrow) lies outside of the FLEX joint alignment (dotted arrows). 


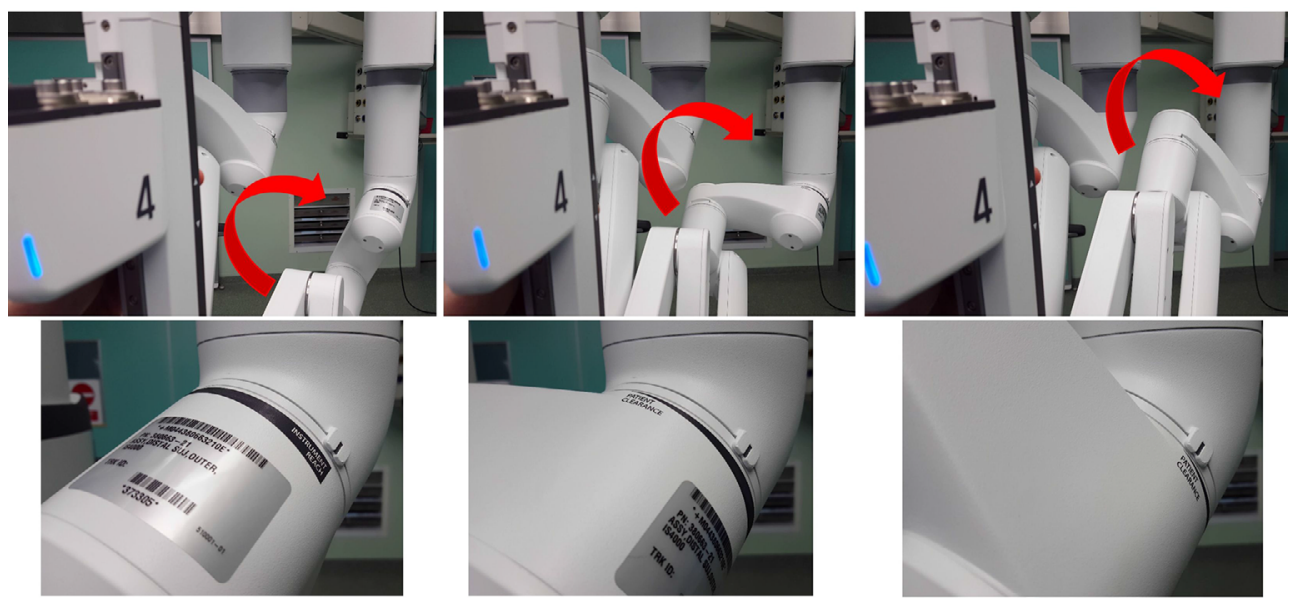

Figure 3 Movement of patient clearance joints during adjustment of patient clearance and instrument reach.

Notes: As patient clearance is increased, the joints rotate axially clockwise away from the patient and the preceding arm.

now have the flexibility of visualizing the surgical field through any of the 8 -mm ports. Compared to the earlier $\mathrm{dV}$ systems, the $30^{\circ}$ endoscope can be inverted from the surgeon console without the assistant having to remove and reinstall the scope. With the new endoscope, there is no longer a need for draping, focusing, white balancing, or calibration, although Kallingal et al reported color fidelity inconsistencies especially when there was blood in the operative field. ${ }^{35}$ Patel et al also reported a reduction in image clarity with the smaller endoscope, although this was subsequently addressed by software upgrades. ${ }^{39}$

The latest development in line with the $\mathrm{Xi}$ is the Trumpf Medical TruSystem 7000dV operating table (TS7000dV; TRUMPF Medizin Systeme GmbH \& Co. KG, Saalfeld, Germany). The $7000 \mathrm{dV}$ features integrated table motion (ITM), which allows the patient to be dynamically positioned while surgery is in progress. This can be performed without removing the instruments or undocking the ports. Apart from allowing gravity to provide optimal exposure at various quadrants of the abdominal cavity, ITM can also reduce complications from a prolonged Trendelenburg position by tilting the table to extreme positions only when necessary. ${ }^{40}$ This synergism of technology would be ideal for multiquadrant colorectal surgery.

While several authors have questioned the role of robots in hemicolectomies, the Xi may be of benefit when performing complete mesocolic excision (CME) and intracorporeal anastomoses. ${ }^{41}$ Hohenberger et al first described their technique of CME and central vascular ligation (CVL) in 2009, reporting a reduction in 5-year locoregional recurrence rate for 1329 patients from $6.5 \%$ to $3.6 \% .^{42}$ This survival advantage was attributed to meticulous mesocolic plane surgery. ${ }^{43}$ Reports from Japan focusing on CVL also showed impressive results from D3 lymphadenectomy. ${ }^{44,45}$ In their systematic review, Killeen et al reported 5-year local recurrence rate, overall survival rate, and disease-free survival rate of $4.5 \%, 58.1 \%$, and $77.4 \%$, respectively. ${ }^{46}$ However, studies comparing laparoscopic excision to open $\mathrm{CME}$ raised issues regarding the completeness of laparoscopic excision for tumors near the flexures or in the transverse colon. ${ }^{47,48}$ Authors attributed this to the technical difficulty of achieving a proximal ligation of the middle colic vessels laparoscopically, possibly explaining why transverse colectomies were excluded from most trials comparing laparoscopic versus open surgery for colorectal cancer. The steep learning curve was also emphasized by Melich et al in their experience with laparoscopic right hemicolectomy and $\mathrm{CME} .{ }^{49}$ While the literature on robotic CME remains sparse, several authors have commented on the potential for its development, citing its stable camera platform and precise instrumentation..$^{50-53}$ Using the older $\mathrm{dV}$ $\mathrm{Si}$, Trastulli et al showed in their series of 20 patients how a surgeon at the beginning of his learning curve for robotic right hemicolectomy managed to complete all cases without conversion or intraoperative morbidity, and achieve a mean hospital stay of 4.5 days (range, $3.5-7) .{ }^{54}$ Considering that performing CVL for right hemicolectomy along the axis of the superior mesenteric vein would involve a wide operative field from the right iliac fossa to the mid-transverse colon, the multiquadrant capabilities of the Xi make it well suited for this task. Similarly, intracorporeal bowel anastomosis has commonly been eschewed due to its perceived difficulty. ${ }^{55}$ Robotic assistance has been reported to simplify and hasten the process due to its endowrist movements facilitating intracorporeal suturing. ${ }^{41,56}$ Instead of concentrating on the known longer operative time, future studies should focus on the impact of robotics on increasing the rates of CME 
and intracorporeal anastomosis in minimally invasive colectomies, highlighting the benefits of ergonomics and how the technology makes the completion of these challenging procedures more feasible.

\section{Use of the $X i$ in TME}

Rectal dissection is possibly the procedure that holds the greatest potential for robotics to establish a role in colorectal surgery. Performing a nerve-preserving dissection within a narrow pelvis laparoscopically is technically demanding. Factors contributing to this include (1) a potentially unstable assistant-dependent scope view, (2) operator tremor that is compounded by the fulcrum effect of a laparoscopic port, (3) limited degrees of movement from a straight-shaft instrument, and (4) the reliance on an experienced assistant to provide optimal traction. The limitations of laparoscopy were evident from the $16 \%$ rectal cancer circumferential resection margin (CRM) positivity rate reported in the MRC CLASICC trial. ${ }^{4}$ The authors of the trial also reported a high conversion rate to open surgery of $34 \%$ in patients with rectal cancer, with an increase in postoperative morbidity and mortality in these patients. With further developments in laparoscopy, the subsequent COLOR II and COREAN trials saw the participation of surgeons with greater operative experience. ${ }^{6,57}$ While the MRC CLASICC trial included 27 participating centers with individual surgeon experience of only 20 prior procedures, the surgeons from the three centers in the COREAN trial had a median case load of 75 cases before commencement of the study. The results from these later trials were comparatively superior, with CRM positivity rates of $9.5 \%$ and $2.9 \%$, and conversion rates of $16 \%$ and $1.2 \%$, respectively. The more recent ACOSOG Z6051 and ALaCaRT trials also reported CRM positivity rates of $12.1 \%$ and $7 \%$, and conversion rates of $11.3 \%$ and $9 \%$, respectively. ${ }^{58,59}$ Both trials, however, had failed to show the non-inferiority of laparoscopy versus open surgery for rectal cancer.

While we await the final results from one of the largest multinational randomized controlled trials comparing laparoscopic versus robotic rectal cancer surgery, the interim analysis of the ROLARR trial has failed to demonstrate any statistically significant differences between the two arms. ${ }^{60}$ This has been criticized to be due to the lower-than-expected $12.2 \%$ conversion rate in the laparoscopic arm - the power calculation for this randomized study had been based on the results of the MRC CLASICC trial. In the only meta-analysis consisting solely of randomized controlled trials, Liao et al showed a significantly lower conversion rate in robotic TME than laparoscopy (OR 0.25, 95\% CI 0.07-0.91, $p=0.04$ ). ${ }^{14}$
The authors also reported a shorter time to recovery of bowel function in favor of robotics (OR $0.54,95 \%$ CI -0.93 to $-0.14, p=0.008)$. One of the most updated meta-analyses that reviewed 24 studies between January 2010 and October 2015 concluded that the conversion rates, estimated blood loss, and length of hospital stay were significantly lower in robotic surgery. ${ }^{20}$ The operative times and total costs were similar to laparoscopy, and there was no significant difference in complication rates and oncological outcomes. The publications by Xiong et al and Wang et al reported superior oncological outcomes in favor of robotics, with CRM positivity rates of $2.74 \%$ versus $5.78 \%$ for robotics and laparoscopy, respectively. ${ }^{27-29}$ Analysis of the pooled data also revealed a significantly lower conversion rate (OR $0.23,95 \%$ CI 0.10 $0.52, p=0.0004)$ and a lower incidence of erectile dysfunction (OR 0.09, 95\% CI 0.02-0.41, $p=0.002$ ) in robotic TME. These studies attribute the superior results of robotics to (1) a stable three-dimensional high-definition camera system and three additional working arms that are entirely controlled by the surgeon, (2) tremor filtering, (3) endowrist instruments with $7^{\circ}$ of movement, and (4) an ergonomic operating position. In the $\mathrm{Xi}$, thinner robotic arms and longer instruments effectively reduce external arm collisions and enable greater reach down the pelvis. The outer yaw, outer pitch, and range of axial insertion for the $\mathrm{dV} \mathrm{Xi}$ instruments are $504^{\circ}, 177^{\circ}$, and 13.5 inches. The same specifications for the $\mathrm{dV}$ Si were $336^{\circ}, 149^{\circ}$, and 11.5 inches, respectively.

An EndoWrist ${ }^{\circledR}$ Stapler has also been designed for use with the $\mathrm{Xi}$. Inserted through a $12-\mathrm{mm}$ robotic port, it features a range of wristed articulation $-54^{\circ}$ up-down and $108^{\circ}$ side-side - facilitating the formation of an optimally orientated staple line during anorectal transection. This addresses one of the main challenges of laparoscopic TME - ergonomically performing a satisfactory low rectal transection in a narrow pelvis. In addition to its maneuverability, the stapler incorporates SmartClamp technology which provides feedback to the surgeon regarding the compatibility of the cartridge staple height with the thickness of the target tissue. By providing direct control from the surgeon console, the endoscopic stapler not only reduces the reliance on an experienced bedside assistant but also avoids the need to undock any of the robotic arms to provide working space for a handheld endoscopic stapler.

\section{Extending its role to single-site and natural-orifice surgery}

A systematic review consisting mainly of general surgical procedures demonstrated the safety and feasibility of the $\mathrm{dV}$ 
single-site platform, although the authors recognized its limitations in surgeries that span a larger operative field. ${ }^{61}$ Surgeries that are performed in confined spaces stand to benefit most from the wristed instrumentation of robotics. A recent development in colorectal surgery that has been receiving much attention is the transanal approach to performing TME (TaTME). Most TaTME studies to date have been conducted using conventional laparoscopic instruments. ${ }^{62,63}$ Atallah et al published their experience with robotic transanal surgery in a cadaveric model in 2011, and subsequently reported the successful completion of robotic TaTME in human cases, concluding that the technique was feasible. ${ }^{64-66}$ In 2015, Gómez Ruiz et al reported results of their pilot study, and Huscher et al published one of the largest series of robotic TaTME - both groups demonstrated feasibility of the technique with satisfactory oncological and operative results. ${ }^{67,68}$ Kuo et al reported their experience with a combined robotic approach to TaTME and radical proctectomy. ${ }^{69}$ Their technique involved conventional robotic instrumentation for the transanal phase, followed by incorporation of the dV Si Single-Site ${ }^{\circledR}$ surgical platform for the abdominal phase. The authors postulated that the slimmer arms of the $\mathrm{Xi}$ would improve the robot docking process and result in less external arm collision.

The medical technology industry recognizes the need for improved instrument platforms to overcome the challenges associated with natural-orifice surgery. The dV Sp and single-site instruments for the $\mathrm{Xi}$ have already received FDA clearance, and we expect them to be implemented in colorectal surgery soon.

\section{Applicability of the $\mathbf{X} \mathbf{i}$ - overcoming the learning curve}

In a study by Stefanidis et al of 34 medical students without prior laparoscopic suturing experience, robotic assistance enabled the participants to complete their suturing task faster, with higher precision and fewer errors compared to laparoscopy. ${ }^{70}$ The students also showed a significant improvement in their performance using robotic assistance, highlighting the learning curve of laparoscopic suturing. After test completion, the participants indicated on the NASA-TLX workload assessment questionnaire that the task was significantly more difficult to perform with conventional laparoscopy. Pigazzi et al also showed a benefit in terms of shortening the learning curve in rectal surgery using a robotic platform. ${ }^{71}$ They reported a reduction in operative time during the first 20 cases of robotic, with a rapid transfer of surgical skills from open to the robotic approach. This result was consistent with reports by other surgeons with limited experience in minimally invasive colorectal surgery. ${ }^{72,73}$ Several reports using CUSUM analytics demonstrated that the learning phase for robotic colorectal surgery consisted of 25-35 cases. ${ }^{74-76} \mathrm{~A}$ recent review by Jiménez-Rodríguez et al calculated that the mean number of cases required for a surgeon to be classified as an expert in robotic rectal cancer surgery was $39 .^{77}$ In comparison, the learning curve for laparoscopic colorectal surgery varies widely, with an international multicenter analysis by Miskovic et al reporting a range of 88-152 cases. ${ }^{78}$ Kayano et al reported a stabilization of operative time for laparoscopic low anterior resections at 50 cases, with conversion rates decreasing significantly only after the 150 th case. ${ }^{79}$ An insightful comment by the authors was that laparoscopic surgery cannot be performed alone by a single expert surgeon - the roles of the "scopist" to control vision and assistants to expose the surgical field in a limited space are also important. By assuming control of the endoscope, active instruments, and assistant robotic arm, the robotic surgeon has the potential to extend his experience, skill, and control to every aspect of the surgery. Instead of having to overcome the learning curves and to match the capabilities of, potentially, three individuals involved in a surgery, the focus can now be placed on the sole operator behind the robotic console. This would ultimately reduce the reliance on trained assistants, address issues of manpower scarcity, and have a far-reaching impact on curtailing rising healthcare cost.

Duty hour restrictions and work regulations have resulted in surgical residents having a more limited exposure and experience in training. ${ }^{80}$ In an electronic survey on the laparoscopic skills of fellows, program directors responded that $30 \%$ of fellows could not atraumatically manipulate tissue, $26 \%$ could not recognize anatomical planes, and $56 \%$ could not suture. ${ }^{81}$ Due to the numerous constraints placed on residency programs, simulation-based training has become an essential component of surgical education. ${ }^{82}$ While laparoscopic simulators are often criticized for the lack of realism in tactile feedback compared to live surgery, robotic simulators are ideal in mimicking the actual instrumentation. Indeed, surgeons practice on the da Vinci Surgical System (dVSS) console when training using the dV skills simulator (Intuitive Surgical).

While the robot may not offer significant benefits to the experienced laparoscopic surgeon, it is certainly an enabler, allowing a novice operator to master more complex procedures through a shorter learning curve without compromising the quality of surgery and safety of the patient. 


\section{Conclusion}

While earlier generations of robots have not managed to show unequivocal evidence of superiority over conventional laparoscopy, this latest $\mathrm{dV}$ surgical system is a quantum leap in innovation and is much more versatile compared to its predecessors. The integrated accessories - staplers, energy devices, advanced imaging technology - rival the armamentarium of equipment developed for conventional laparoscopy. The $\mathrm{dV}$ $\mathrm{Xi}$ simplifies multiquadrant surgery through its improved docking interface and extended reach. This new system has the potential to facilitate the widespread application of robotics in colorectal surgery, and may eventually justify its cost.

\section{Acknowledgment}

The authors thank Ms Yang Peiling from Transmedic Pte Ltd, Singapore, for providing console training and technical support. For Figure 1 the three patients provided consent for the images to be published.

\section{Disclosure}

The authors have no financial relationships with any pharmaceutical or device company, and no conflict of interest to declare in this work.

\section{References}

1. Semm K. Endoscopic appendectomy. Endoscopy. 1983;15(2):59-64.

2. Jacobs M, Verdeja JC, Goldstein HS. Minimally invasive colon resection (laparoscopic colectomy). Surg Laparosc Endosc. 1991;1(3):144-150.

3. Clinical Outcomes of Surgical Therapy Study Group, Sargent DJ, Wieand HS, Fleshman J. A comparison of laparoscopically assisted and open colectomy for colon cancer. $N$ Engl J Med. 2004;350(20): 2050-2059.

4. Guillou PJ, Quirke P, Thorpe H, et al; MRC CLASICC trial group. Shortterm endpoints of conventional versus laparoscopic-assisted surgery in patients with colorectal cancer (MRC CLASICC trial): multicentre, randomised controlled trial. Lancet. 2005;365(9472):1718-1726.

5. Green BL, Marshall HC, Collinson F, et al. Long-term follow-up of the Medical Research Council CLASICC trial of conventional versus laparoscopically assisted resection in colorectal cancer. Br J Surg. 2013;100(1):75-82.

6. Bonjer HJ, Deijen CL, Abis GA, et al; COLOR II Study Group. A randomized trial of laparoscopic versus open surgery for rectal cancer. N Engl J Med. 2015;372:1324-1332.

7. Moloo H, Haggar F, Martel G, et al. The adoption of laparoscopic colorectal surgery: a national survey of general surgeons. Can J Surg. 2009;52(6):455-462.

8. Schoetz DJ Jr. Evolving practice patterns in colon and rectal surgery. J Am Coll Surg. 2006;203(3):322-327.

9. Kwon S, Billingham R, Farrokhi E, et al; Surgical Care and Outcomes Assessment Program (SCOAP) Collaborative. Adoption of laparoscopy for elective colorectal resection: a report from the Surgical Care and Outcomes Assessment Program. J Am Coll Surg. 2012;214(6): 909-918. e1.

10. Weber PA, Merola S, Wasielewski A, Ballantyne GH. Teleroboticassisted laparoscopic right and sigmoid colectomies for benign disease. Dis Colon Rectum. 2002;45(12):1689-1694; discussion 1695-1696.
11. deSouza AL, Prasad LM, Park JJ, Marecik SJ, Blumetti J, Abcarian H. Robotic assistance in right hemicolectomy: is there a role? Dis Colon Rectum. 2010;53(7):1000-1006.

12. Rawlings AL, Woodland JH, Vegunta RK, Crawford DL. Robotic versus laparoscopic colectomy. Surg Endosc. 2007;21(10):1701-1708.

13. Memon S, Heriot AG, Murphy DG, Bressel M, Lynch AC. Robotic versus laparoscopic proctectomy for rectal cancer: a meta-analysis. Ann Surg Oncol. 2012;19(7):2095-2101.

14. Liao G, Zhao Z, Lin S, et al. Robotic-assisted versus laparoscopic colorectal surgery: a meta-analysis of four randomized controlled trials. World J Surg Oncol. 2014;12:122.

15. Delaney CP, Lynch AC, Senagore AJ, Fazio VW. Comparison of robotically performed and traditional laparoscopic colorectal surgery. Dis Colon Rectum. 2003;46(12):1633-1639.

16. Aly EH. Robotic colorectal surgery: summary of the current evidence. Int J Colorectal Dis. 2014;29(1):1-8.

17. Trastulli S, Cirocchi R, Desiderio J, et al. Robotic versus laparoscopic approach in colonic resections for cancer and benign diseases: systematic review and meta-analysis. PLoS One. 2015;10(7):e0134062.

18. Kim NK, Kang J. Optimal total mesorectal excision for rectal cancer: the role of robotic surgery from an expert's view. J Korean Soc Coloproctol. 2010;26(6):377-387.

19. Trastulli S, Farinella E, Cirocchi R, et al. Robotic resection compared with laparoscopic rectal resection for cancer: systematic review and metaanalysis of short-term outcome. Colorectal Dis. 2012;14(4):e134-e156.

20. Zhang X, Wei Z, Bie M, Peng X, Chen C. Robot-assisted versus laparoscopic-assisted surgery for colorectal cancer: a meta-analysis. Surg Endosc. 2016;30(12):5601-5614.

21. Jiménez Rodríguez RM, Díaz Pavón JM, de La Portilla de Juan F, Prendes Sillero E, Hisnard Cadet Dussort JM, Padillo J. [Prospective randomised study: robotic-assisted versus conventional laparoscopic surgery in colorectal cancer resection]. Cir Esp. 2011;89(7):432-438. Spanish [with English abstract].

22. Park JS, Choi GS, Park SY, Kim HJ, Ryuk JP. Randomized clinical trial of robot-assisted versus standard laparoscopic right colectomy. $\mathrm{Br} J$ Surg. 2012;99(9):1219-1226.

23. Xu H, Li J, Sun Y, et al. Robotic versus laparoscopic right colectomy: a meta-analysis. World J Surg Oncol. 2014;12:274.

24. Chang YS, Wang JX, Chang DW. A meta-analysis of robotic versus laparoscopic colectomy. J Surg Res. 2015;195(2):465-474.

25. Zarak A, Castillo A, Kichler K, de la Cruz L, Tamariz L, Kaza S. Robotic versus laparoscopic surgery for colonic disease: a meta-analysis of postoperative variables. Surg Endosc. 2015;29(6):1341-1347.

26. Deutsch GB, Sathyanarayana SA, Gunabushanam V, et al. Robotic vs. laparoscopic colorectal surgery: an institutional experience. Surg Endosc. 2012;26(4):956-963.

27. Xiong B, Ma L, Zhang C, Cheng Y. Robotic versus laparoscopic total mesorectal excision for rectal cancer: a meta-analysis. J Surg Res. 2014;188(2):404-414.

28. Xiong B, Ma L, Huang W, Zhao Q, Cheng Y, Liu J. Robotic versus laparoscopic total mesorectal excision for rectal cancer: a meta-analysis of eight studies. J Gastrointest Surg. 2015;19(3):516-526.

29. Wang Y, Zhao GH, Yang H, Lin J. A pooled analysis of robotic versus laparoscopic surgery for total mesorectal excision for rectal cancer. Surg Laparosc Endosc Percutan Tech. 2016;26(3):259-264.

30. Ozben V, Cengiz TB, Atasoy D, et al. Is da Vinci Xi better than da Vinci Si in robotic rectal cancer surgery? Comparison of the 2 generations of da Vinci systems. Surg Laparosc Endosc Percutan Tech. 2016;26(5):417-423.

31. Protyniak B, Jorden J, Farmer R. Multiquadrant robotic colorectal surgery: the da Vinci Xi vs Si comparison. J Robot Surg. Epub 2017 Mar 8.

32. Morelli L, Guadagni S, Di Franco G, et al. Use of the new da Vinci $\mathrm{Xi}^{\circledR}$ during robotic rectal resection for cancer: a pilot matched-case comparison with the da Vinci $\mathrm{Si}^{\circledR}$. Int J Med Robot. 2017;13(1).

33. Hagen ME, Jung MK, Ris F, et al. Early clinical experience with the da Vinci Xi Surgical System in general surgery. J Robot Surg. Epub 2016 Dec 27. 
34. Tamhankar AS, Jatal S, Saklani A. Total robotic radical rectal resection with da Vinci Xi system: single docking, single phase technique. Int $J$ Med Robot. 2016;12(4):642-647.

35. Kallingal GJ, Swain S, Darwiche F, et al. Robotic partial nephrectomy with the Da Vinci Xi. Adv Urol. 2016;2016:9675095.

36. Koh DC, Tsang CB, Kim SH. A new application of the four-arm standard da Vinci ${ }^{\circledR}$ surgical system: totally robotic-assisted left-sided colon or rectal resection. Surg Endosc. 2011;25(6):1945-1952.

37. Bae SU, Baek SJ, Hur H, Baik SH, Kim NK, Min BS. Robotic left colon cancer resection: a dual docking technique that maximizes splenic flexure mobilization. Surg Endosc. 2015;29(6):1303-1309.

38. Ngu JC, Sim S, Yusof S, Ng CY, Wong AS. Insight into the da Vinci ${ }^{\circledR}$ $\mathrm{Xi}$ - technical notes for single-docking left-sided colorectal procedures. Int J Med Robot. Epub 2016 Dec 23.

39. Patel MN, Aboumohamed A, Hemal A. Does transition from the da Vinci Si to Xi robotic platform impact single-docking technique for robot-assisted laparoscopic nephroureterectomy? BJU Int. 2015;116(6): 990-994.

40. MorelliL, PalmeriM, Guadagni S, etal. Use of anew integrated tablemotion for the da Vinci Xi in colorectal surgery. Int JColorectal Dis. 2016;31(9): 1671-1673.

41. Park SY, Choi GS, Park JS, Kim HJ, Choi WH, Ryuk JP. Robot-assisted right colectomy with lymphadenectomy and intracorporeal anastomosis for colon cancer: technical considerations. Surg Laparosc Endosc Percutan Tech. 2012;22(5):e271-e276.

42. Hohenberger W, Weber K, Metzel K, Papadopoulos T, Merkel S. Standardized surgery for colonic cancer: complete mesocolic excision and central ligation - technical notes and outcome. Colorectal Dis. 2009;11(4):354-364.

43. West NP, Hohenberger W, Weber K, Perrakis A, Finan PJ, Quirke P. Complete mesocolic excision with central vascular ligation produces an oncologically superior specimen compared with standard surgery for carcinoma of the colon. J Clin Oncol. 2012;28(2):272-278.

44. Kanemitsu Y, Komori K, Kimura K, Kato T. D3 lymph node dissection in right hemicolectomy with a no-touch isolation technique in patients with colon cancer. Dis Colon Rectum. 2013;56(7):815-824.

45. Watanabe T, Muro K, Ajioka Y, et al; Japanese Society for Cancer of the Colon and Rectum. Japanese Society for Cancer of the Colon and Rectum (JSCCR) guidelines 2016 for the treatment of colorectal cancer. Int J Clin Oncol. Epub 2017 Mar 27.

46. Killeen S, Mannion M, Devaney A, Winter DC. Complete mesocolic resection and extended lymphadenectomy for colon cancer: a systematic review. Colorectal Dis. 2014;16(8):577-594.

47. Kontovounisios C, Kinross J, Tan E, Brown G, Rasheed S, Tekkis P. Complete mesocolic excision in colorectal cancer: a systematic review. Colorectal Dis. 2015;17(1):7-16.

48. Gouvas N, Pechlivanides G, Zervakis N, Kafousi M, Xynos E. Complete mesocolic excision in colon cancer surgery: a comparison between open and laparoscopic approach. Colorectal Dis. 2012;14(11):1357-1364.

49. Melich G, Jeong DH, Hur H, et al. Laparoscopic right hemicolectomy with complete mesocolic excision provides acceptable perioperative outcomes but is lengthy - analysis of learning curves for a novice minimally invasive surgeon. Can J Surg. 2014;57(5):331-336.

50. Spinoglio G, Marano A, Bianchi PP, et al. Robotic right colectomy with modified complete mesocolic excision: long-term oncologic outcomes. Ann Surg Oncol. 2016;23 Suppl 5:684-691.

51. Bae SU, Jeong WK, Baek SK. Robotic complete mesocolic excision and intracorporeal anastomosis using a robotic stapler for right-sided colon cancer with reduced-port access. Dis Colon Rectum. 2017;60(4):456.

52. Ozben V, Baca B, Atasoy D, et al. Robotic complete mesocolic excision for right-sided colon cancer. Surg Endosc. 2016;30(10):4624-4625.

53. Aghayeva A, Baca B, Atasoy D, et al. Robotic complete mesocolic excision for splenic flexure of colon cancer. Dis Colon Rectum. 2016;59(11): 1098.

54. Trastulli S, Desiderio J, Farinacci F, et al. Robotic right colectomy for cancer with intracorporeal anastomosis: short-term outcomes from a single institution. Int J Colorectal Dis. 2013;28(6):807-814.
55. Jamali FR, Soweid AM, Dimassi H, Bailey C, Leroy J, Marescaux J. Evaluating the degree of difficulty of laparoscopic colorectal surgery. Arch Surg. 2008;143(8):762-767; discussion 768.

56. Jayaraman S, Quan D, Al-Ghamdi I, El-Deen F, Schlachta CM. Does robotic assistance improve efficiency in performing complex minimally invasive surgical procedures? Surg Endosc. 2010;24(3):584-588.

57. Jeong SY, Park JW, Nam BH, et al. Open versus laparoscopic surgery for mid-rectal or low-rectal cancer after neoadjuvant chemoradiotherapy (COREAN trial): survival outcomes of an open-label, non-inferiority, randomised controlled trial. Lancet Oncol. 2014;15(7):767-774.

58. Fleshman J, Branda M, Sargent DJ, et al. Effect of laparoscopic-assisted resection vs open resection of stage II or III rectal cancer on pathologic outcomes. the ACOSOG Z6051 randomized clinical trial. JAMA. 2015;314(13):1346-1355.

59. Stevenson AR, Solomon MJ, Lumley JW, et al; ALaCaRT Investigators. Effect of laparoscopic-assisted resection vs open resection on pathological outcomes in rectal cancer: the ALaCaRT randomized clinical trial. JAMA. 2015;314(13):1356-1363.

60. Collinson FJ, Jayne DG, Pigazzi A, et al. An international, multicenter, prospective, randomised, controlled, unblinded, parallel-group trial of robotic-assisted versus standard laparoscopic surgery for the curative treatment of rectal cancer. Int J Colorectal Dis. 2012;27(2):233-241.

61. Morelli L, Guadagni S, Di Franco G, Palmeri M, Di Candio G, Mosca F. Da Vinci single site ${ }^{\circ}$ surgical platform in clinical practice: a systematic review. Int J Med Robot. 2016;12(4):724-734.

62. Sylla P, Rattner DW, Delgado S, Lacy AM. NOTES transanal rectal cancer resection using transanal endoscopic microsurgery and laparoscopic assistance. Surg Endosc. 2010;24(5):1205-1210.

63. Leroy J, Barry BD, Melani A, Mutter D, Marescaux J. No-scar transanal total mesorectal excision: the last step to pure NOTES for colorectal surgery. JAMA Surg. 2013;148(3):226-230.

64. Atallah SB, Albert MR, deBeche-Adams TH, Larach SW. Robotic TransAnal Minimally Invasive Surgery in a cadaveric model. Tech Coloproctol. 2011;15(4):461-464.

65. Atallah S, Nassif G, Polavarapu H, et al. Robotic-assisted transanal surgery for total mesorectal excision (RATS-TME): a description of a novel surgical approach with video demonstration. Tech Coloproctol. 2013;17(4):441-447.

66. Atallah S, Martin-Perez B, Pinan J, et al. Robotic transanal total mesorectal excision: a pilot study. Tech Coloproctol. 2014;18(11):1047-1053.

67. Gómez Ruiz M, Parra IM, Palazuelos CM, et al. Robotic-assisted laparoscopic transanal total mesorectal excision for rectal cancer: a prospective pilot study. Dis Colon Rectum. 2015;58(1):145-153.

68. Huscher CG, Bretagnol F, Ponzano C. Robotic-assisted transanal total mesorectal excision: the key against the Achilles' heel of rectal cancer? Ann Surg. 2015;261(5):e120-e121.

69. Kuo LJ, Ngu JC, Tong YS, Chen CC. Combined robotic transanal total mesorectal excision (R-taTME) and single-site plus one-port (R-SSPO) technique for ultra-low rectal surgery-initial experience with a new operation technique. Int J Colorectal Dis. 2017;32(2):249-254.

70. Stefanidis D, Wang F, Korndorffer JR Jr, Dunne JB, Scott DJ. Robotic assistance improves intracorporeal suturing performance and safety in the operating room while decreasing operator workload. Surg Endosc. 2010;24(2):377-382.

71. Pigazzi A, Luca F, Patriti A, et al. Multicentric study on robotic tumorspecific mesorectal excision for the treatment of rectal cancer. Ann Surg Oncol. 2010;17(6):1614-1620.

72. Kim JC, Yang SS, Jang TY, Kwak JY, Yun MJ, Lim SB. Open versus robot-assisted sphincter-saving operations in rectal cancer patients: techniques and comparison of outcomes between groups of 100 matched patients. Int J Med Robot. 2012;8(4):468-475.

73. Kim YW, Lee HM, Kim NK, Min BS, Lee KY. The learning curve for robot-assisted total mesorectal excision for rectal cancer. Surg Laparosc Endosc Percutan Tech. 2012;22(5):400-405.

74. Bokhari MB, Patel CB, Ramos-Valadez DI, Ragupathi M, Haas EM. Learning curve for robotic-assisted laparoscopic colorectal surgery. Surg Endosc. 2011;25(3):855-860. 
75. Sng KK, Hara M, Shin JW, Yoo BE, Yang KS, Kim SH. The multiphasic learning curve for robot-assisted rectal surgery. Surg Endosc. 2013;27(9):3297-3307.

76. Jiménez-Rodríguez RM, Díaz Pavón JM, de la Portilla de Juan F, PrendesSillero E, Dussort HC, Padillo J. Learning curve for robotic-assisted laparoscopic rectal cancer surgery. Int J Colorectal Dis. 2013;28(6):815-821.

77. Jiménez-Rodríguez RM, Rubio-Dorado-Manzanares M, Diaz Pavón JM, et al. Learning curve in robotic rectal cancer surgery: current state of affairs. Int J Colorectal Dis. 2016;31(12):1807-1815.

78. Miskovic D, Ni M, Wyles SM, Tekkis P, Hanna GB. Learning curve and case selection in laparoscopic colorectal surgery: systematic review and international multicenter analysis of 4852 cases. Dis Colon Rectum. 2012;55(12):1300-1310.
79. Kayano H, Okuda J, Tanaka K, Kondo K, Tanigawa N. Evaluation of the learning curve in laparoscopic low anterior resection for rectal cancer. Surg Endosc. 2011;25(9):2972-2979.

80. Nasca TJ, Day SH, Amis ES Jr; ACGME Duty Hour Task Force. The new recommendations on duty hours from the ACGME Task Force. $N$ Engl J Med. 2010;363(2):e3.

81. Mattar SG, Alseidi AA, Jones DB, et al. General surgery residency inadequately prepares trainees for fellowship: results of a survey of fellowship program directors. Ann Surg. 2013;258(3): $440-449$.

82. Scott DJ, Dunnington GL. The new ACS/APDS Skills Curriculum: moving the learning curve out of the operating room. $J$ Gastrointest Surg. 2008;12(2):213-221.
Robotic Surgery: Research and Reviews

\section{Publish your work in this journal}

Robotic Surgery: Research and Reviews is an international, peer reviewed open access, online journal publishing original research, commentaries, reports, and reviews on the theory, use and application of robotics in surgical interventions. Articles on the use of supervisory-controlled robotic systems, telesurgical devices, and shared-control systems are

\section{Dovepress}

invited. The manuscript management system is completely online and includes a very quick and fair peer review system, which is all easy to use. Visit http://www.dovepress.com/testimonials.php to read real quotes from published authors. 